\title{
ANÁLISE DE UMA [IN]CORPORAÇÃO DA ABORDAGEM SISTÊMICA NO CURRÍCULO DE CIÊNCIAS DE MATO GROSSO DO SUL
}

\author{
Ana Laura Dias De Souza
}

Universidade Estadual Paulista - UNESP, Mestrado em Educação, Presidente Prudente, SP. E-mail: annalauradias@gmail.com

\section{RESUMO}

O artigo discute a importância de uma abordagem sistêmica no processo de ensino e aprendizagem das Ciências em detrimento da fragmentação de saberes promovida pelo método reducionista que ainda influencia a educação escolar, prejudicando a formação de um espírito científico-pesquisador nos estudantes. Percebe-se que a discussão da importância de uma abordagem sistêmica no estudo dos seres vivos já está presente em documentos oficiais como os PCNs e DCNs. Este trabalho procura então examinar a efetiva incorporação destas orientações no Referencial Curricular da Rede Estadual de Ensino de Mato Grosso do Sul, tomando como conteúdo de referência o estudo do corpo humano no oitavo ano do ensino fundamental. A análise das orientações pedagógicas presentes no documento se mostram contraditórias com a própria organização curricular, o que vem contribuindo na construção de uma visão fragmentada do corpo humano pelos alunos, transferindo-se aos professores a tarefa promover a integração entre estes saberes.

Palavras-Chave: pensamento sistêmico; currículo; Mato Grosso do Sul; corpo humano.

\section{ANALYSIS OF AN INCORPORATION OF SYSTEMIC APPROACH IN CURRICULUM SCIENCE OF SOUTH MATO GROSSO STATE}

\begin{abstract}
This article argues the importance of a systemic approach in the teaching and learning of science at the prejudice of the fragmentation of knowledge promoted by the reductionist method that still influences the school education, hampering the formation of a scientific researcher spirit in students. It is noticed that the discussion of the importance of a systemic approach in to study of living beings is already present in official documents as the PCNs and DCNs. This paper then examines the effective incorporation of these guidelines in Referential Curriculum of State Network of South Mato Grosso State, taking as reference content the study of human body in the eighth year of elementary school. The analysis of educational guidance in the document shows contradictory with the own curricular organization, the which has contributed to building a fragmented view of the human body by students, transferring for teachers the task of promoting the integration of this knowledge.
\end{abstract}

Keywords: systems thinking; curriculum; South Mato Grosso State; Human Body 


\section{INTRODUÇÃO}

Embora se apresentem variadas designações para a aqui denominada "abordagem sistêmica" no estudo de Ciências, conforme relato de Behrens (1999, p. 387) que juntamente com "Boaventura Santos (1987), Pimentel (1993), Moraes (1997) denomina o avanço como paradigma emergente; Cardoso (1995), Brandão e Crema (1991), como paradigma holístico; Prigogine (1986) e Capra (1996), como paradigma sistêmico"; este se caracteriza pela produção de um conhecimento que leva em consideração que as propriedades essenciais de um organismo, ou sistema vivo, são propriedades do todo, que nenhuma das partes possui. Um sistema vivo não é uma soma de elementos como faria supor o raciocínio cartesiano, que defende que todo fenômeno biológico pode ser explicado por princípios físicos e químicos, ao contrário, o sistema vivo é um todo não redutível a suas partes. Por sua vez, a superação de uma visão newtoniana-cartesiana de mundo exige repensar o sistema de valores então subjacentes a esse paradigma.

A psicologia cognitiva já provou que o conhecimento progride mais quando integra conhecimentos do que quando se propõe a abstrair e sofisticar conhecimentos particulares. A exemplo do que vinha acontecendo nas pesquisas científicas desde o século XVI e XVII, a escola se fragmentou em busca da especialização, dividindo primeiramente os saberes em áreas e, dentro delas, priorizando alguns conteúdos. O filósofo e sociólogo francês Edgar Morin (2002), destaca que a inteligência que só sabe separar, fragmenta o complexo do mundo em pedaços separados, fraciona os problemas, unidimensionaliza o multidimensional, atrofia as possibilidades de compreensão e reflexão, eliminando assim as oportunidades de um julgamento corretivo e de uma visão a longo prazo. Assim a forte disciplinaridade escolar tem impedido que o aluno desenvolva uma noção adequada das relações entre os saberes, desvinculando-os de sua realidade e deixando de promover a significação necessária ao seu aprendizado.

Esta concepção de como uma visão fragmentada do conhecimento pode ser nociva para a formação do espírito cientifico do aluno, porém, não é nova. No Brasil, no ano de 1998, o Ministério da Educação colocou a disposição da comunidade escolar o documento intitulado Parâmetros Curriculares Nacionais (PCN) uma proposta de reorganização curricular coerente com os ideais presentes na Lei no 9.394/96 que estabelece as diretrizes e bases da educação nacional. Os PCNs de Ciências Naturais de Terceiro e Quarto Ciclos do Ensino Fundamental já trazem como primeiro ponto dos objetivos gerais das Ciências Naturais a compreensão da natureza como um todo dinâmico e nos critérios para seleção de conteúdos, enfatiza que estes: "devem favorecer a construção, pelos estudantes, de uma visão de mundo como um todo formado por elementos inter-relacionados, entre os quais o ser humano, agente de transformação." (BRASIL, 1998, p. 35).

Mais recentemente, na divulgação das novas Diretrizes Curriculares Nacionais para a Educação Básica orienta-se na formação curricular uma organização do trabalho pedagógico em eixos temáticos, propiciando assim a concretização de uma proposta pedagógica centrada na visão interdisciplinar, superando o isolamento das pessoas e a compartimentalização de conteúdos rígidos. (BRASIL, 2013). No mesmo sentido, a proposta preliminar de uma Base Nacional Comum Curricular (BNCC) que está sendo discutida e reformulada atualmente, como exigência das próprias Diretrizes, da LDB e do Plano Nacional de Educação vigentes, tem proposto o ensino de ciências em "unidades de aprendizagem visando manter a articulação entre os conhecimentos e proporcionar a continuidade de estudos ao longo de toda a Educação Básica". (BRASIL, 2016, p. 439)

Há que se destacar que as Diretrizes e PCNs, apesar de apresentar uma estrutura curricular completa, foram apresentados como parâmetros indicativos, e de acordo com a LDB vigente, as redes de ensino tiveram a autonomia e compromisso de elaborar diretrizes curriculares próprias, visando atender às particularidades e necessidades de cada região. 
Assim sendo, este artigo objetiva trazer algumas reflexões sobre a incorporação de uma abordagem sistêmica no ensino de Ciências presente Referencial Curricular do estado de Mato Grosso do Sul, e apesar de vários autores proporem o ensino interdisciplinar como forma de atenuar essa fragmentação escolar, acreditamos que é necessário primeiramente analisar se há avanços em uma abordagem sistêmica dentro das temáticas propostas na própria disciplina, pois como alçamos progredir em um diálogo entre as disciplinas se mesmos os conteúdos propostos dentro destas não interagirem entre si? Assim posto, escolhemos como tema norteador o estudo do corpo humano dentro do Referencial Curricular citado, visto que os PCNs também já se mostram claros ao orientar na temática que o estudante deve "perceber a vida humana, seu próprio corpo, como um todo dinâmico, que interage com o meio em sentido amplo, pois tanto a herança biológica quanto as condições culturais, sociais e afetivas refletem-se no corpo." (BRASIL, 1998, p. 22).

\section{METODOLOGIA}

A parte empírica do estudo se dá através de análise documental com cunho qualitativo. A análise documental compreende "quaisquer materiais escritos que possam ser usados como fonte de informação sobre o comportamento humano" (LÜDKE e ANDRÉ, 1986, p. 38). Esta técnica permite identificar informações factuais, baseadas em pressupostos de interesse, e oferecem evidências para responder um problema.

Os documentos analisados são o Referencial Curricular do Ensino Fundamental da Rede Estadual de Ensino de Mato Grosso do Sul atualmente utilizado, bem como as demais orientações curriculares nacionais subjacentes a este ensino que influenciaram em seu processo de construção. Mais especificamente é analisada a organização curricular proposta para o ensino de ciências no estudo do corpo humano no Ciclo II, concentrado ao longo dos quatro bimestres do 8 o ano do Ensino Fundamental. $O$ estudo dos referidos documentos se dá com enfoque nas questões de interesse, que nesta pesquisa se concentra na análise de aspectos presentes nos materiais de ensino que podem ou não contribuir para construção de uma visão fragmentada do corpo humano pelos alunos e avanços na abordagem sistêmica.

\section{RESULTADOS}

\section{O novo Referencial Curricular de Mato Grosso do Sul e o espaço da abordagem sistêmica no estudo do corpo humano}

A mais recente proposta curricular do MS voltada ao Ensino Fundamental foi elaborada somente após dez anos da divulgação dos PCN. Segundo Bertoletti (2013, p. 950) ao que tudo indica a "elaboração e publicação desse novo currículo deveu-se a exigências legais, no que diz respeito à implantação do Ensino Fundamental de nove anos", regulamentado pela Lei no 11.274 de 06 de fevereiro de 2006 e não para suprir as necessidades previstas no cotidiano das escolas estaduais. O referencial foi disponibilizado às unidades escolares em 2008 e após algumas reformulações, uma nova e até aqui última versão foi distribuída aos professores em 2012. Em seus textos de embasamento teórico pedagógico, distribuídos em diversos assuntos no início do Referencial, desde concepções sobre Educação, Escola e Currículo, até orientações para o Ensino Fundamental, Médio, Educação Especial, do Campo, Indígena, Ambiental entre outras, se percebe no documento, além da previsível influência dos Parâmetros Curriculares Nacionais, a forte incorporação de princípios presentes nas Diretrizes Curriculares Nacionais Gerais para a Educação Básica (DCNs) publicados no ano de 2010.

As disciplinas estão agrupadas no Currículo por áreas de conhecimento, sendo que para cada uma delas é disponibilizado um texto com orientações pedagógicas denominadas "Visão de Área", seguida pela organização de conteúdos a serem trabalhados ao longo dos quatro bimestres letivos, as competências e habilidades a serem atingidas e por fim, as referências bibliográficas. 
Assim, embora o documento traga em sua apresentação que este foi "pensado de forma a proporcionar a todos os educadores uma visão sistêmica do currículo com a possibilidade de observação da horizontalidade e verticalidade dos conteúdos expostos, de forma a contextualizálos, interagindo os diversos conhecimentos e componentes curriculares/disciplinas" (MATO GROSSO DO SUL, 2012, p.9), a forma como é estruturada os componentes possibilita uma interpretação dúbia:

[...] pois, ao mesmo tempo em que exalta um conhecimento coeso e totalizante das disciplinas que enfatizam a construção do conhecimento relacional, tratam-nas separadamente, como unidades individuais em si mesmas, sem reforçar a proposição inicial de trabalhar com os componentes curriculares construindo e desenvolvendo habilidades e competências que possibilitem aos alunos terem uma compreensão relacional entre os conteúdos das outras disciplinas. (Debona, Ribeiro e Pinto, 2015, p. 21).

Quanto às orientações da visão de área do ensino de ciências da natureza presentes no Referencial, estas se desenvolvem em apenas duas páginas, em texto com uma crítica contundente ao paradigma reducionista, que segundo Behrens (2005, apud MATO GROSSO DO SUL, 2012, p.280) tem consolidado de "um modo de ensinar fragmentado, em que o objetivo da ciência é descobrir a verdade, o objetivo do professor é transmitir conhecimento e ao estudante cabe apenas decorá-lo passivamente". Nesse sentido, ressalta que é fundamental que o educador compreenda a teia das relações existentes entre todas as coisas, para que possa pensar a ciência una e múltipla simultaneamente.

Apesar das breves orientações presentes no Currículo para o ensino de ciências criticarem a forma essencialmente disciplinar de organização do ensino, logo em seguida, na seleção de conteúdos a serem abordados, percebe-se o total distanciamento da proposta sistêmica então sugerida, sendo estes organizados da forma essencialmente padronizada e fragmentada há décadas em cada série do Ensino Fundamental do Ciclo II: basicamente solo, ar e água no sexto ano, os seres vivos e sua classificação no sétimo ano, a anatomia e funcionamento do corpo humano no oitavo e as transformações físicas e químicas no nono ano.

Quanto ao conteúdo norteador deste artigo, o estudo do corpo humano na disciplina de Ciências, este se concentra predominantemente no oitavo ano do ensino fundamental, dividido nos quatro bimestres do ano letivo, sendo apresentado inicialmente no primeiro bimestre como coleção de células, tecidos, órgãos e seguindo posteriormente o estudo dos demais sistemas. Permeando estes conteúdos são propostos temas transversais na área da saúde, como exemplo hábitos alimentares saudáveis, durante o estudo do sistema digestorio e consumo de álcool e problemas no trânsito, quando se estuda o sistema nervoso.

Além de determinar os conteúdos para cada bimestre, o referencial também traz uma lista de "competências e habilidades" a serem desenvolvidas no aluno para cada conteúdo. Cabendo aqui um questionamento das próprias "competências e habilidades" elencadas no currículo: apesar da padronização na organização dos conteúdos, a integração entre os sistemas do corpo humano são apontados como competências e habilidades que os alunos devem adquirir, exemplificando o que é solicitado no segundo bimestre: "demonstrar as integrações e funções entre os sistemas digestório, cardiovascular, respiratório e excretor". (MATO GROSSO DO SUL, 2012, p.297).

Embora descritas como tal, percebe-se uma confusão no uso destes termos, deslocados de seu contexto e dos conceitos originais explicitados nos próprios documentos curriculares. Perrenoud (2000, p. 19) define competência como "a faculdade de mobilizar um conjunto de recursos cognitivos (saberes, capacidades, informações, etc.) para solucionar com pertinência e 
eficácia uma série de situações." O conceito de habilidade varia conforme os diferentes autores, mas em geral, são consideradas como algo menos amplo do que as competências. Assim, a competência estaria constituída por diversas habilidades. Os PCN assim explicitam os desafios do ensino por competências:

Um ensino por competências nos impõe um desafio que é organizar o conhecimento a partir não da lógica que estrutura a ciência, mas de situações de aprendizagem que tenham sentido para o aluno, que the permitam adquirir um instrumental para agir em diferentes contextos e, principalmente, em situações inéditas de vida. (BRASIL, 2006, p. 35)

O próprio referencial curricular ressalta também que "as competências não eliminam os conteúdos; elas direcionam a seleção, visto que o importante não é a quantidade de informações, mas a capacidade de lidar com elas" (MATO GROSSO DO SUL, 2012, p.14). O que vemos, porém, elencado no currículo como competências e habilidades, apenas para citar alguns exemplos no estudo dos conteúdos do corpo humano no oitavo ano do Ensino Fundamental: "definir os níveis de organização do corpo humano", "conhecer as defesas do corpo", "explicar a relação entre os órgãos do sentido e percepção do ambiente", "conceituar cromossomos e genes" (idem, p. 297298), se constituem antes, mais como uma forma de reprodução de um conhecimento específico adquirido pelo aluno, a ser traduzido em comportamento observáveis que podem então, ser mais facilmente submetidos ao controle externo. Como observa Macedo (2002, p. 122) essa normalização da ação acaba por tirar da noção de competência aquilo que a caracteriza, ou seja, "a mobilização de diferentes esquemas para atuar em uma situação específica, esquemas esses que não podem ser previamente estabelecidos até porque são diferenciados por sujeitos de aprendizagem."

Ao professor, diante de tantas incongruências presentes no currículo, cabe exercer sua autonomia em sala de aula, para promover esta articulação, esta organização entre os saberes adquiridos pelos alunos e aquisição de competências, de recursos que possam ser utilizados diante de situações-problemas. Como o próprio Referencial Curricular procura resguardar: "cabe à escola complementá-lo de acordo com suas especificidades, com autonomia metodológica, para ampliar conhecimentos, conteúdos, habilidades, competências e, ainda, o desenvolvimento de um processo contextualizado com a realidade local". (idem, p.9)

No entanto, cabe ressaltar que essa aparente autonomia é regrada e vigiada pelos planejamentos de aula registrados mensalmente ou quinzenalmente, de acordo com a escolha prévia da unidade escolar, por meio de uma plataforma online.

\section{DISCUSSÃO}

Percebe-se claramente que, embora o próprio currículo de ciências do Estado de Mato Grosso do Sul que os professores dispõem para seu planejamento de aulas esteja organizado de forma essencialmente fragmentada, a despeito de suas próprias considerações teóricas, cabe aos docentes auxiliar os alunos a desenvolverem as integrações necessárias entres os conteúdos aprendidos. No estudo do corpo humano transfere-se ao professor a tarefa de juntar, integrar, dar vida ao corpo humano entregue a ele de forma esquartejada durante os bimestres.

Enquanto docente desta rede estadual já me perguntava como este processo de ensino seria possível e como Trivelato (2005, p. 127) trago o questionamento se há "espaço no currículo para que se apresente o corpo humano por inteiro, numa visão integrada e holística?".

\section{CONCLUSÃO}

Trivelato (2005) admite que, mesmo verificando iniciativas positivas no sentido de um estudo mais integrado em Ciências, não se pode admitir que os currículos já tenham incorporado 
uma abordagem holística no conhecimento sobre o corpo humano, citando entre outros fatores o peso da tradição curricular, o tempo necessário para que novos conhecimentos se façam presentes em cursos de formação inicial de professores e o tempo de incorporação desses conhecimento pelos materiais didáticos.

De antemão, em uma análise prévia, após mais de dez anos desta análise de Trivelato e quase vinte da divulgação dos PCNs, percebe-se que embora de uma maneira confusa e contraditória, os currículos oficiais, como do estado do MS, orientam um ensino integrado, rompendo com a visão reducionista. Para efetivação deste ensino o principal recurso utilizado pelo professor em sala de aula ainda é o livro didático, mesmo com o advento de novos recursos no mundo digital, sendo escolhidos àqueles que melhor satisfazem os conteúdos programáticos propostos no currículo de ciências. Assim sendo, torna-se necessário verificar como vem sendo abordado o estudo do corpo humano nos livros didáticos aprovados no PNLD avaliando possíveis avanços na incorporação sistêmica do estudo no corpo humano nestes materiais que possam auxiliar o professor em seu planejamento de aulas. Quanto à formação inicial e continuada do professor faz-se também necessário que seja repensada e discutida, de forma que estes já tenham contato com novo paradigma e gradativamente a complexidade possa chegar à educação escolar. Embora se saiba que uma formação atualizada com os novos saberes não garante uma mudança radical na prática pedagógica do professor em sala de aula, todavia tem o poder provocá-lo a refletir sobre sua ação docente.

Sabemos também que não haverá uma transição rápida de uma abordagem a outra, nem tampouco esperamos completa anulação de um paradigma conservador-cartesiano em nossas escolas. Mas a falta de integração entre os saberes escolares enfrenta dificuldades que não podem mais ser ignorados ou ficarem no campo teórico das orientações curriculares. Vale lembrar que nossos corpos biológicos que ao longo do tempo fomos aprendendo a ver apenas em seu aspecto funcionalista e desintegrado é também um corpo produtor de cultura, capaz de interagir com outros corpos e se reintegrar, produzindo novas formas de conhecimentos.

\section{REFERÊNCIAS}

BEHRENS, Marilda Aparecida. A prática pedagógica e o desafio do paradigma emergente. Revista Brasileira de Estudos Pedagógicos, Brasília, v. 80, n. 1996, p. 383-403, set./dez. 1999. Disponível em <http://rbep.inep.gov.br/index.php/rbep/article/view/977/951>. Acesso em: 05 jul. 2016.

BERTOLETTI, Estela Natalina Mantovani . História da disciplina Língua Portuguesa em Mato Grosso do Sul (1977-2008): um estudo de propostas curriculares. Revista de Educação Publica (UFMT) , v. 22, p. 951-972, set./dez. 2013.

BRASIL, Ministério da Educação, Base Nacional Comum Curricular: 2a versão revista. 2016. Disponível em:< http http://basenacionalcomum.mec.gov.br/documentos/bncc2versao.revista.pdf>. Acesso em 20 jul. 2016.

BRASIL, Ministério da Educação, Conselho Nacional de Educação. Diretrizes Curriculares Nacionais Gerais para a Educação Básica. Parecer 11/2010, Brasília, DF, 2013.

BRASIL, Ministério da Educação, Secretaria de Educação Fundamental. Parâmetros Curriculares Nacionais: Ciências Naturais. Brasília: Ministério da Educação, SEF, 1998.

DEBONA, J. J. ; RIBEIRO, Renilson Rosa ; PINTO, A. A. Por um ensino da história de Mato Grosso do Sul: implicações dos documentos referenciais para o enfoque regional no ensino de História no Ensino Fundamental. Historia \& Perspectivas (UFU) , v. 53, p. 315-348, jul./dez. 2015. 
LÜKDE, M. e ANDRÉ, M. E. D. A. Pesquisa em Educação: abordagens qualitativas. São Paulo: Editora Pedagógica e Universitária Ltda, 99p., 1986.

MACEDO, E. F. Currículo e Competência. In: LOPES, A. C; MACEDO, E. (Org.). Disciplinas e integração curricular: história e políticas. Rio de Janeiro: DP\&A, 2002, p. 115 - 143.

MATO GROSSO DO SUL. Referencial Curricular da Educação Básica da Rede Estadual de Ensino/MS - Ensino Fundamental. Secretaria de Estado de Mato Grosso do Sul, 2012.

MORIN, Edgar. A cabeça bem-feita: repensar a reforma, reformar o pensamento. 7. ed. Rio de Janeiro: Bertrand Brasil, 2002.

PERRENOUD, Philipe. Construir as competências desde a escola. Porto Alegre: Artes Médicas, 2000.

TRIVELATO, S. L. F. Que corpo/ ser humano habita nossas escolas? In: Amorim, A. C. et al. Ensino de Biologia: conhecimentos e valores em disputa. Niterói: Eduff, 2005. p.121-130. 